\title{
Spatial scaling of plant and bird diversity from 50 to 10,000 ha in a lowland tropical rainforest
}

\author{
Richard J. Hazell ${ }^{1}$ (1) $\cdot$ Kryštof Chmel $^{2,3} \cdot$ Jan Riegert ${ }^{4} \cdot$ Luda Paul $^{5} \cdot$ Brus Isua $^{5} \cdot$ Graham S. Kaina $^{5,6} \cdot$ Pavel Fibich $^{2,4}$. \\ Kenneth Molem $^{5} \cdot$ Alan J. A. Stewart ${ }^{1} \cdot$ Mika R. Peck $^{1} \cdot$ George D. Weiblen ${ }^{7} \cdot$ Vojtech Novotny $^{2,4}$
}

Received: 23 June 2020 / Accepted: 21 April 2021 / Published online: 5 May 2021

(c) The Author(s) 2021

\begin{abstract}
While there are numerous studies of diversity patterns both within local communities and at regional scales, the intermediate scale of tens to thousands of $\mathrm{km}^{2}$ is often neglected. Here we present detailed local data on plant communities (using $20 \times 20 \mathrm{~m}$ plots) and bird communities (using point counts) for a 50 ha ForestGEO plot in lowland rainforest at Wanang, Papua New Guinea. We compare these local diversity patterns with those documented in the surrounding 10,000 ha of lowland rainforest. Woody plant species richness was lower within 50 ha ( $88 \%$ of 10,000 ha richness), even when both were surveyed with identical sampling effort. In contrast, bird communities exhibited identical species accumulation patterns at both spatial scales. Similarity in species composition (Chao-Jaccard) remained constant while similarity in dominance structure (Bray-Curtis) decreased with increased distance between samples across the range from $<1$ to $13.8 \mathrm{~km}$ for both plant and bird communities. The similarity decay was more rapid in plants, but in both cases was slow. The results indicate low to zero beta-diversity at the spatial scale represented here, particularly for birds but also for woody plants. A 50 ha plot provided a highly accurate representation of broader-scale diversity and community composition within 10,000 ha for birds, and a relatively good representation for woody plants. This suggests potential for wider generalization of data from ForestGEO plots which are almost always locally unreplicated, at least for those in lowland tropical forest.
\end{abstract}

Keywords Beta-diversity $\cdot$ Community composition $\cdot$ ForestGEO plot $\cdot$ Rarefaction $\cdot$ Species richness

Communicated by Kendi Davies.

Richard J. Hazell

richard.hazell@hotmail.co.uk; r.j.hazell@sussex.ac.uk

1 Department of Evolution, Behaviour and Environment, School of Life Sciences, University of Sussex, Brighton BN1 9QG, UK

2 Biology Centre, Institute of Entomology, Czech Academy of Sciences, Branišovská 1760, 37005 Ceske Budejovice, Czech Republic

3 Faculty of Science, Charles University, Viničná 7, 12844 Prague, Czech Republic

4 Faculty of Science, University of South Bohemia, Branišovská 31, 37005 Ceske Budejovice, Czech Republic

5 New Guinea Binatang Research Centre, Madang, Madang, Papua New Guinea

6 Papua New Guinea Forest Research Institute, Lae, Morobe, Papua New Guinea

7 Department of Plant Biology, University of Minnesota, Saint Paul, MN 55108, USA

\section{Introduction}

Diversity patterns are scale-dependent (Willis and Whittaker 2002; Rahbek 2005; Jackson and Fahrig 2015), and as such the magnitude of diversity is likely to vary with geographic scale (Crawley and Harral 2001; Rahbek 2005). For example, Lennon et al. (2001) found that patterns of British bird species richness at a scale of $10 \mathrm{~km}$ were statistically unrelated to those at a scale of $90 \mathrm{~km}$. Scale may be measured in terms of grain, i.e. the size of individual observation units (as in the above case), or extent, i.e. the total area covered by the observations within a survey (Wiens 1989). The manipulation of either of these aspects is likely to affect the outcomes of diversity estimates in different ways (Nekola and White 1999). With this in mind, the extent to which diversity estimates can reasonably be extrapolated to areas larger than the area sampled is limited (Colwell and Coddington 1994). Any such inferences require an understanding of taxon-specific patterns of alpha-diversity in local communities and 
beta-diversity, i.e. turnover in species composition between sites.

Both alpha- and beta-diversity are likely driven by a variety of ecological mechanisms, from niche-based processes such as environmental filtering and biotic interactions to local stochastic processes and spatial factors such as dispersal limitation, with little consensus over which processes are dominant in structuring communities (Macarthur and Levins 1967; Vandermeer 1972; Hubbell 2001; Veech and Crist 2007; Rosindell et al. 2011; Myers et al. 2013; Yang et al. 2015). In reality it is likely that the relative importance of the different mechanisms shaping both alpha- and betadiversity varies according to the spatial scale at which analyses are conducted (Rahbek and Graves 2001; De Cáceres et al. 2012; Barton et al. 2013; Chase 2014; Melchior et al. 2017). In a meta-analysis of plant and animal species richness gradients across scales, Field et al. (2009) found that climate and productivity were the best predictors of richness at the largest grain and extent sizes, while area was strongest at small $\left(<10 \mathrm{~km}^{2}\right)$ and biotic interactions at intermediate scales $\left(10-500 \mathrm{~km}^{2}\right)$. In addition, the importance of different processes may vary between taxa. Different taxa may show contrasting diversity patterns across scales (Qian 2009; Zellweger et al. 2017) due to variation in energy sources and dispersal ability, as well as the scale at which habitats are perceived and niches defined (Barton et al. 2013).

Plants and birds are both important components of tropical rainforest systems, but the extent to which diversity estimates made at one scale translate to another may differ between them. For example, plant distribution may be influenced locally by fine-grained environmental characteristics such as soil composition which do not directly affect birds (Idárraga et al. 2016). Nevertheless, bird community structure is clearly affected by variations in habitat structure created by plants themselves (Jankowski et al. 2013). Reif et al. (2008) found that patterns in bird community structure were primarily attributable to variation in habitat composition at small spatial scales $(0.5 \mathrm{~km})$, while dispersal limitation and historical factors became more important at a scale of $8 \mathrm{~km}$. Studies focussing on plants show varying results, with some attributing large-scale patterns to broad-scale environmental gradients and finer-scale patterns to stochastic processes (Laliberté et al. 2008), and others showing apparently contrasting patterns (Freestone and Inouye 2006). Evidence for the processes structuring plant diversity in diverse uniform habitats such as lowland rainforests in the absence of clear climatic and environmental gradients is currently sparse, although some studies indicate that spatial processes such as dispersal limitation may predominate here at intermediate scales (Condit et al. 2002; Myers et al. 2013).

Forest dynamics plots provide an effective means of assessing long term changes in biodiversity patterns of vegetation mapped in great detail but on a relatively small spatial scale of 15-50 ha (Condit 1995). The Forest Global Earth Observatory (ForestGEO) now comprises a global network of such plots (Anderson-Teixeira et al. 2015). The comprehensive inventories of all woody plants $\geq 1 \mathrm{~cm}$ diameter at breast height (DBH) in these plots quantify plant species diversity in a standardised manner for forests across the tropics (Ashton 1995; Condit 1998). The detailed spatially explicit information on plants in forest dynamics plots presents an opportunity for complementary surveys of animal communities, including birds, which has not been used so far.

Interestingly, most of the ForestGEO plots lack complementary estimates of plant diversity for the surrounding wider areas of $10-100 \mathrm{~km}^{2}$, relying thus on extrapolation of species diversity patterns across wider spatial scales (Kochummen and LaFrankie 1990; Lee et al. 2002; Kenfack et al. 2007). Systematic quantitative surveys of biodiversity within tens to hundreds of $\mathrm{km}^{2}$ of relatively homogeneous habitats, such as lowland rainforests, are rare, compared to local community data on the one hand and data on regional floras and faunas on the other (e.g. Novotny et al. 2006; Basset et al. 2012). This reliance on extrapolation is presumably based on the long-recognised principle that diversity should increase with the size of area sampled (MacArthur and Wilson 1967). However, uniformity of patterns and processes across scales cannot be assumed (Wiens 1989; Scheiner et al. 2000). Scaling curves may vary from linear to more complex logistic patterns, depending on the range of scales involved and the characteristics of the environment and the taxa being studied (Barton et al. 2013). For example, increasing spatial extent may cause a rapid increase in diversity at fine scales due to stochastic variation in species occupancy patterns, which slows down at intermediate scales as the number of new species added relative to the regional pool decreases (the rate of this deceleration varying among taxa with an organism's perception of habitat heterogeneity and its dispersal ability). At large scales, increases in diversity may start to accelerate again as separate biogeographic regions with distinct evolutionary histories are encompassed (Barton et al. 2013). This high potential for variation demonstrates how simple diversity extrapolations may produce results that vary considerably from reality.

This study aims to fill two gaps in rainforest biodiversity studies by (i) providing detailed spatially explicit data on community composition of birds within a 50 ha ForestGEO plot in Papua New Guinea (the Wanang forest dynamics plot, or FDP), thus matching similarly detailed information on plants, and (ii) examining the plant and bird data from the FDP in the context of the surrounding 10,000 ha of lowland rainforest (the Wanang Conservation Area, or WCA), focussing on the alpha- and beta-diversity patterns. Similarly to many lowland rainforests, the habitat surrounding the FDP is relatively uniform at the scale explored in this study, both 
in terms of elevation and climate (Paijmans 1976). Therefore we expect that environmental factors will play relatively little role in shaping alpha- and beta-diversity patterns of woody plants and birds at this scale, and that dispersal limitation will play a more important role (Myers et al. 2013). As birds are better dispersers than plants, our hypotheses thus primarily reflect the differences in dispersal limitation between the two taxa. We hypothesize that: (i) woody plant species richness will be higher in the WCA than in the FDP, while bird species richness in the FDP and WCA will be similar, and (ii) woody plant species dissimilarity will increase with increased distance between plots, while bird dissimilarity will show little or no change with increasing distance, indicating higher beta-diversity of plants than birds at the scale explored in this study.

By including data from both plants and birds and thus incorporating a broad trophic range, this study aims to provide a more complete picture of spatial diversity patterns than those produced by studies focussing on plants alone. Such studies currently comprise the vast majority of data from forest dynamics plots (e.g. Hubbell and Foster 1983; Condit et al. 1996; Plotkin et al. 2001; Lee et al. 2002; Volkov et al. 2005, 2009; Kenfack et al. 2007; Metz 2012; Chen et al. 2016). Indeed, although the nature of the data obtained by surveys of plant and bird communities using vegetation plots and bird point counts respectively is essentially identical, comprising the list of all individuals from a defined area often between 0.05 and 1 ha, the two taxa are rarely studied simultaneously (but see e.g. Schulze et al. 2004). This study is additionally the first to our knowledge to specifically assess the suitability of forest dynamics plots as a monitoring tool for assessing bird diversity. Finally, by keeping grain size constant between surveys this study specifically investigates the effect of spatial extent on the diversity patterns observed.

\section{Materials and methods}

\section{Study site}

The Wanang Conservation Area (WCA) comprises 10,770 ha of primary lowland rainforest in the Middle Ramu region of Madang Province, northern Papua New Guinea. The forest is classified as tropical, wet mixed evergreen (Paijmans 1976). The climate, with an average temperature of $25.8{ }^{\circ} \mathrm{C}$ and annual precipitation of $4000 \mathrm{~mm}$ (Vincent et al. 2015), has a mild dry season from July to September. Although a lowland site, the topography is variable and comprises steep ridges separated by a network of streams and rivers. The sample sites range in elevation between 80 and $250 \mathrm{~m}$ above sea level, encompassing the full topographical range of the WCA. The 50 ha forest dynamics plot (FDP) is located centrally within the WCA (Fig. 1) and comprises a $1000 \times 500 \mathrm{~m}$ rectangle divided into 1250 individual $20 \times 20 \mathrm{~m}$ plots. Its location was selected in part to encompass as fully as possible the topographical range of the WCA, with elevation ranging from 90 to $180 \mathrm{~m}$ a.s.1.

\section{Vegetation survey}

Plants in the FDP were surveyed using a standard methodology for ForestGEO plots (see Anderson-Teixeira et al. 2015). That is, all free-standing trees with $\mathrm{DBH} \geq 1 \mathrm{~cm}$ were tagged, mapped, measured and identified to species level. Only woody plants $\geq 5 \mathrm{~cm}$ DBH were included in the present analysis. The WCA was surveyed by a regular grid comprising 43 sites $1.5 \mathrm{~km}$ apart, fitted to the conservation area using ArcGIS 10.02 (Fig. 1). Each sample location included a single $20 \times 20 \mathrm{~m}$ plot, mirroring the sample design of the FDP. All plant stems with $\mathrm{DBH} \geq 5 \mathrm{~cm}$ were measured and identified within each plot. Data collection took place from 4-Oct-2014 to 17-Dec-2014 in the WCA and from 2010 to 2012 in the FDP. In addition to species composition, each plot was characterized by canopy height, canopy closure, total tree basal area, number of stems and plot elevation. These variables were selected to enable characterisation of topographical heterogeneity between plots for both plants and birds (elevation), and of structural habitat heterogeneity between plots for birds (four vegetation characteristics). Canopy closure was assessed in MATLAB version 2015a (Mathworks 2015) by measuring the mean percentage cover of foliage in four canopy photos from each $20 \times 20 \mathrm{~m}$ plot, using code developed by Korhonen and Heikkinen (2009). In the field, sample points were located using GPS (Garmin GPSmap $62 \mathrm{~s}$ ).

\section{Bird survey}

Bird surveys were based on point counts. The FDP was surveyed using a regular grid of 169 points separated by $80 \mathrm{~m}$ along the horizontal and vertical lines parallel to the plot boundaries (Fig. 1). Each point was used for one point count. Bird surveys in the WCA used the same $1.5 \mathrm{~km}$ grid as the vegetation surveys. Forty sample locations were sampled by eight point counts separated by $150 \mathrm{~m}$, with the first point count being coterminous with the $20 \times 20 \mathrm{~m}$ plot of the vegetation survey (Fig. 1). This gave a total of 320 individual point counts.

Point counts followed the same protocol for both sets of surveys. Counts took place between 06:00 and 10:30 am, lasted $10 \mathrm{~min}$ and started after an interval of a few minutes following arrival at each point to minimize the effects of disturbance caused by arrival (Bibby et al. 2000). All individual birds seen or heard were recorded together with an estimate of their distance from the observer. Only birds 


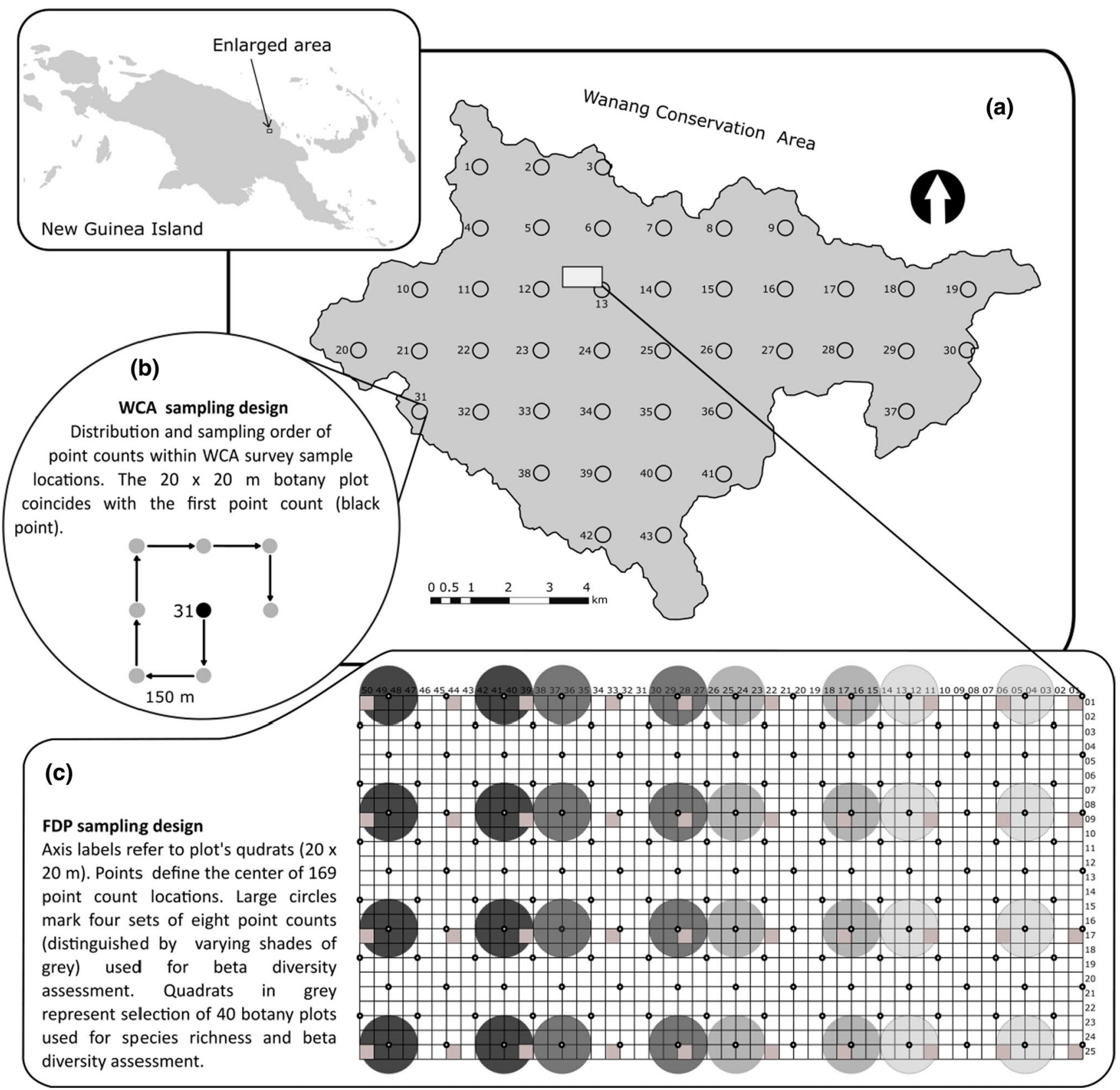

Fig. 1 Map and diagrams showing a geographic location of Wanang Conservation Area (WCA) in New Guinea, b layout of woody plant and bird sampling locations in the WCA (circles) and c sampling design in the 50 ha Forest Dynamics Plot (FDP). One botany plot and

estimated to be within $40 \mathrm{~m}$ of the observers were included in the analysis. To minimize multiple counts of the same individual, multiple conspecifics were recorded only if the observer could be sure they were different individuals (e.g. two birds singing simultaneously). Point counts were always conducted by two observers, one of whom (LP) was present across all surveys to minimize the effects of observer bias. During each point count, an audio recording was made using an Olympus LS-5 Linear PCM digital recorder. This enabled eight point counts were sampled in each location of the WCA. Bird surveys at sampling locations 1,20 and 36 were omitted due to logistical constraints

later identification of misidentified or poorly heard individuals. Field work took place from 4-Oct-2014 to 31-Jan-2015 in the WCA and from 10-Feb-2015 to 6-Mar-2015 in the FDP.

\section{Data analysis}

For both woody plants and birds, species richness for the FDP and WCA were compared using R package "iNEXT" 
for rarefaction and extrapolation of species richness (Hsieh et al. 2016). For plants, $4020 \times 20 \mathrm{~m}$ plots from within the FDP were selected to enable comparison of equivalent sampling effort with the WCA (Fig. 1). Sample-based rarefaction and extrapolation curves for both plant and bird datasets were created using Hill numbers (with $q=0$ ), i.e. species richness unbiased by abundances of individual species (Chao et al. 2014). Sample-based rarefaction was chosen over individual-based since samples approximate more closely independent data points than do individuals and as such account better for natural levels of environmental heterogeneity present (Gotelli and Colwell 2001). A bootstrap method based on 999 random permutations of the data enabled the construction of confidence intervals and comparison of overlap at the maximum point for which sampling effort was equal (40 samples for plants; 169 samples for birds). In addition, the Chao 2 richness estimator (Chao et al. 2005) was calculated for each dataset to give an estimated value of asymptotic species richness.

Plant beta-diversity was analysed using the $4020 \times 20 \mathrm{~m}$ plots from the FDP selected for the species richness analysis, providing a range of pairwise distances between plots from 0.1 to $1.12 \mathrm{~km}$, in addition to the $4320 \times 20 \mathrm{~m}$ plots from the WCA, having pairwise distances ranging from 1.5 to $13.8 \mathrm{~km}$ (Fig. 1). For birds, the 40 individual sample locations combining eight point counts each were used as data points for the WCA. This data structure was mirrored in the FDP by creating four sets of eight adjacent point counts (spaced $160 \mathrm{~m}$ apart, Fig. 1) used as equivalents of the WCA sample locations. The Bray-Curtis dissimilarity and the Chao variant of the Jaccard dissimilarity indices were employed for beta-diversity analyses using the "vegan" package in R (Oksanen et al. 2018). The choice of these indices enabled us to explore dissimilarities based on species composition (Chao-Jaccard) or where the species abundance is also taken into account (Bray-Curtis) (Chao et al. 2005).

For analysis of both plant and bird beta-diversity across space, data from the FDP and WCA were pooled. The community dissimilarity was correlated with distance by plotting the Bray-Curtis and Chao-Jaccard matrices against a between-site distance matrix, using a Mantel test (9999 permutations) with Pearson's correlations. In addition to the analysis on the pooled datasets, we compared variability in dissimilarity between sample locations in each surveyed area (the FDP versus the larger WCA) to reveal whether communities are more similar within the smaller sampling area. Differences in dissimilarity between the FDP and WCA were tested using a permutational MANOVA with 999 permutations provided by function adonis in the "vegan" package (Oksanen et al. 2018).

To determine the relative importance of spatial and environmental variables in determining woody plant and bird community composition, we used CANOCO 5 (Smilauer and
Leps 2014) to perform a Principal Coordinates of Neighbouring Matrices (PCNM) analysis using Canonical Correspondence Analysis (CCA) for the woody plant dataset and Redundancy Analysis (RDA) with forward selection for the bird community dataset. Based on the length of the first Detrended Correspondence Analysis axis, CANOCO 5 recommends either a unimodal (CCA) or linear (RDA) method. The PCNM approach enabled us to separate the effect of space predictors (represented by spatial eigenfunctions corresponding to spatial relationships among the sampling sites) from the effect of primary (environmental) predictors (Legendre and Legendre 2012). The analysis included nine steps: primary predictor test, primary predictor selection by CCA, principal coordinate analysis (PCoA), PCNM for all predictors, PCNM selection, spatial effects analysis, primary predictor effects analysis, joint effects analysis and removal of spatial effects (Smilauer and Leps 2014). Elevation of vegetation plots was tested as the environmental primary predictor of woody plant composition. In the case of bird community composition, we included the following potential predictors in the analysis: canopy closure, tree basal area, total DBH of small $(5-10 \mathrm{~cm} \mathrm{DBH})$ and large stems ( $>40 \mathrm{~cm} \mathrm{DBH}$ ), diversity of trees (Simpson Index) and elevation of sampling location. Elevation was averaged over eight sample points for a given sampling location.

\section{Results}

\section{Species richness of woody plant community}

We recorded a total of 4060 individual woody plants $\geq 5 \mathrm{~cm}$ DBH, representing 379 species, across both surveys. A total of 2119 individual woody plants $\geq 5 \mathrm{~cm}$ DBH were recorded across the 43 sample locations of the WCA survey, representing a total of 317 species. The 40 plots taken from the FDP survey contained 1941 individual woody plants $\geq 5 \mathrm{~cm}$ DBH from 279 species, i.e. 88\% of WCA species richness. A total of 217 species (57.3\%) were present in both surveys. $68.5 \%$ of species (comprising $90 \%$ of abundance) found in the WCA were also present in the FDP, while $77.8 \%$ of species (comprising $94.1 \%$ of abundance) found in the FDP were present in the WCA. The rarefaction curves from both surveys do not appear to approach an asymptote, suggesting greater sampling effort is necessary to achieve accurate species richness estimates (Fig. 2). Nevertheless, the Chao2 richness indicator estimated species richness values of 419.8 (WCA) and 353.1 (FDP). From observed and extrapolated species richness (Fig. 2) a clear separation can be observed between species rarefaction curves for the two surveys. The lack of an overlap of $95 \%$ confidence intervals for the plant data indicates a significantly higher species richness across the WCA than in the FDP. However, despite the difference 

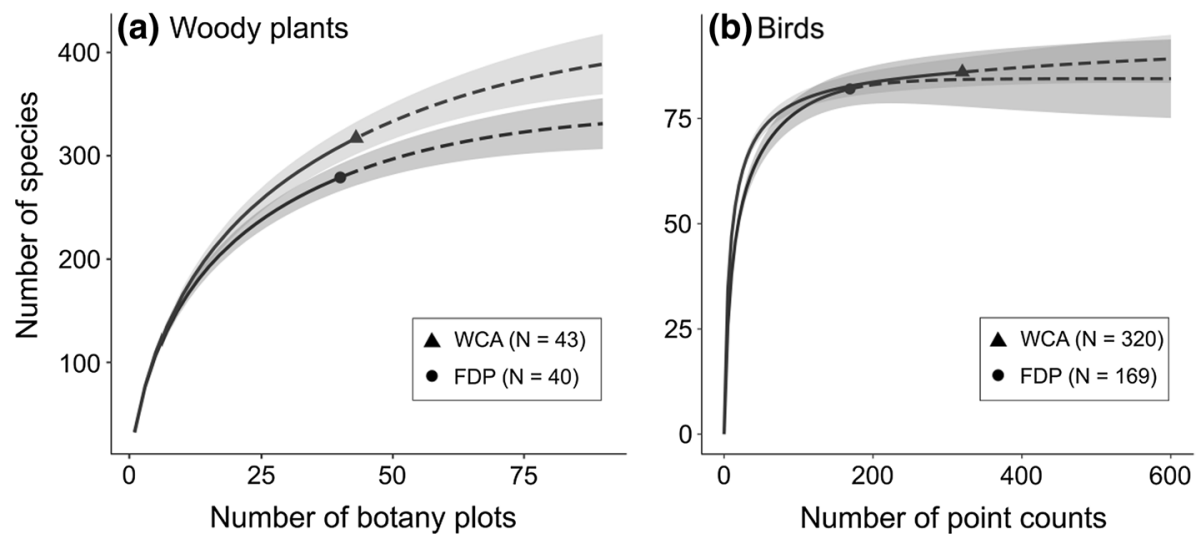

Fig. 2 Species richness rarefaction curves for $\mathbf{a}$ woody plants and $\mathbf{b}$ birds in the WCA and FDP. Solid lines show interpolated rarefaction curves. Dashed lines represent extrapolated rarefactions exceeding our sampling effort. Shaded areas represent $\pm 95 \%$ confidence inter-

vals. Species accumulation was calculated for woody plants from $20 \mathrm{~m} \times 20 \mathrm{~m}$ plots ( $N=43$ and 40 for WCA and FDP, respectively) and for birds from point counts $(N=320$ and 169 for WCA and FDP, respectively)

in species richness, woody plants from the two surveys show very similar dominance structure patterns (Fig. 3 ).

The results described above are supported by a comparison of the WCA dataset (40 plots) and the full FDP dataset (1250 plots). The total species richness ( 452 species) in the latter dataset covering the entirety of the FDP is higher due to a strikingly more intense sampling effort. Nevertheless, the WCA dataset still comprises 53 (16.7\%) unique species (7.3\% of individuals) that did not occur in the full FDP dataset.

\section{Species richness of bird community}

We recorded a total of 6389 individual birds of 93 species across both surveys. This included 4976 individuals of 86 species from the 320 point counts in the WCA and 1420 individuals of 82 species (i.e. 95.3\% of WCA species richness) from the 169 point counts in the FDP. Community composition was similar between the two surveys. A total of 79 species (84.9\%) were present in both surveys.

91.9\% of species (representing 99\% of abundance) from the WCA were also present in the FDP, while $96.3 \%$ of species (representing $99.6 \%$ of abundance) found in the FDP were present in the WCA. In contrast to plants, rarefaction curves showed no significant difference between the two datasets $(95 \% \mathrm{CI})$ for 169 point counts, the highest sample size available for both WCA and FDP (Fig. 2). This overlap persisted even when using $84 \%$ confidence intervals (Fig. S1), a technique which has been shown to robustly mimic 0.05 pairwise statistical tests when comparing species richness values (MacGregor-Fors and Payton 2013). Moreover, unlike plants, rarefaction curves for both bird survey datasets closely approach an asymptote (Fig. 2). Extrapolation using the Chao2 richness indicator produced estimated asymptotic species richness values of 89.3 (WCA) and 83.9 (FDP). Species rank abundance curves (Fig. 3) are similar in shape for the two surveys, although the most common species represented a higher proportion of records at WCA (Pitohui kirhocephalus, $10.9 \%$ of records) than the FDP (Meliphaga sp., 7.6\%).

Fig. 3 Rank dominance for a woody plants and $\mathbf{b}$ birds in the WCA (dashed lines) and FDP (solid lines). Curves show the percentage of all individuals represented by each species $(N=317$ and 279 woody plant species for WCA and FDP, respectively; $N=86$ and 82 bird species for WCA and FDP, respectively)

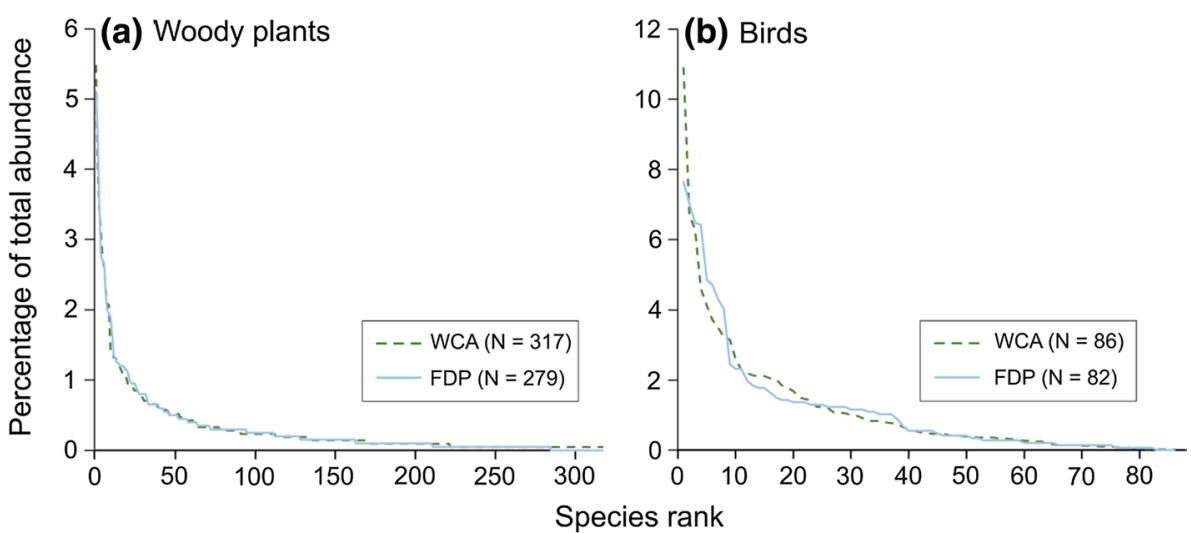




\section{Beta-diversity}

We did not find any relationship between pairwise distance and dissimilarity in woody plant community composition when measured using the Chao-Jaccard dissimilarity index (Fig. 4a; Mantel test, 9999 permutations, $r=0.089$, $p=0.069)$. However, when using the Bray-Curtis index, the dissimilarity of woody plant communities significantly increased with geographic distance (Fig. 4c; Mantel test, 9999 permutations, Mantel $r=0.135, p=0.034$ ). Similarly, when using the Chao-Jaccard dissimilarity estimator, we did not detect a significant relationship between bird community dissimilarity and inter-site distance across the pooled WCA/ FDP sample locations (Fig. 4b; Mantel test, 9999 permutations, Mantel $r=0.033, p=0.296$ ). In contrast, beta-diversity with the Bray-Curtis index did show a positive relationship between community dissimilarity and distance (Fig. 4d; Mantel test, 9999 permutations, $r=0.132, p=0.028$ ).

Dissimilarities (Chao-Jaccard; Bray-Curtis) between sampling locations located within the smaller study area (FDP) were on average lower than those within the larger WCA both for both plants and birds (Fig. S2).

\section{Effect of environmental variables}

A significant proportion of variation in woody plant species composition was explained by elevation of sampling locations (Fig. 5, Table S1; CCA, $F=1.6, p=0.001,22 \%$ of explained variation). Spatial structure of sampling locations, however, accounted for larger proportion of explained variation (77.1\%). The primary (elevation) and space predictors shared $0.9 \%$ of explained variation and together they explained $9 \%$ of the total variation.

Forward selection found canopy closure, number of individual trees within plots and elevation to be the significant primary predictors of bird community composition across the pooled datasets (Fig. 6, Table S1; RDA, canopy closure: $F=2.6, p=0.009$; number of trees: $F=2.0$, $p=0.013$; elevation: $F=2.0, p=0.028$ ). The primary predictors accounted for $40.3 \%$ of explained variation, whereas space accounted for $51.0 \%$ of explained variation (8.7\% of explained variation was shared between primary and space predictors). All predictors explained 29.9\% of the total variation.
Fig. 4 Pairwise relationships of beta-diversity indices and geographical distances between sampling sites, shown for woody plants (a, c) and birds (b, d). We used two dissimilarity indices: Chao-Jaccard $(\mathbf{a}, \mathbf{b})$ and Bray-Curtis (c, d). Linear approximation with shaded area representing standard error was used for significant relationships (Pearson $r$, Mantel test, $p<0.05)$
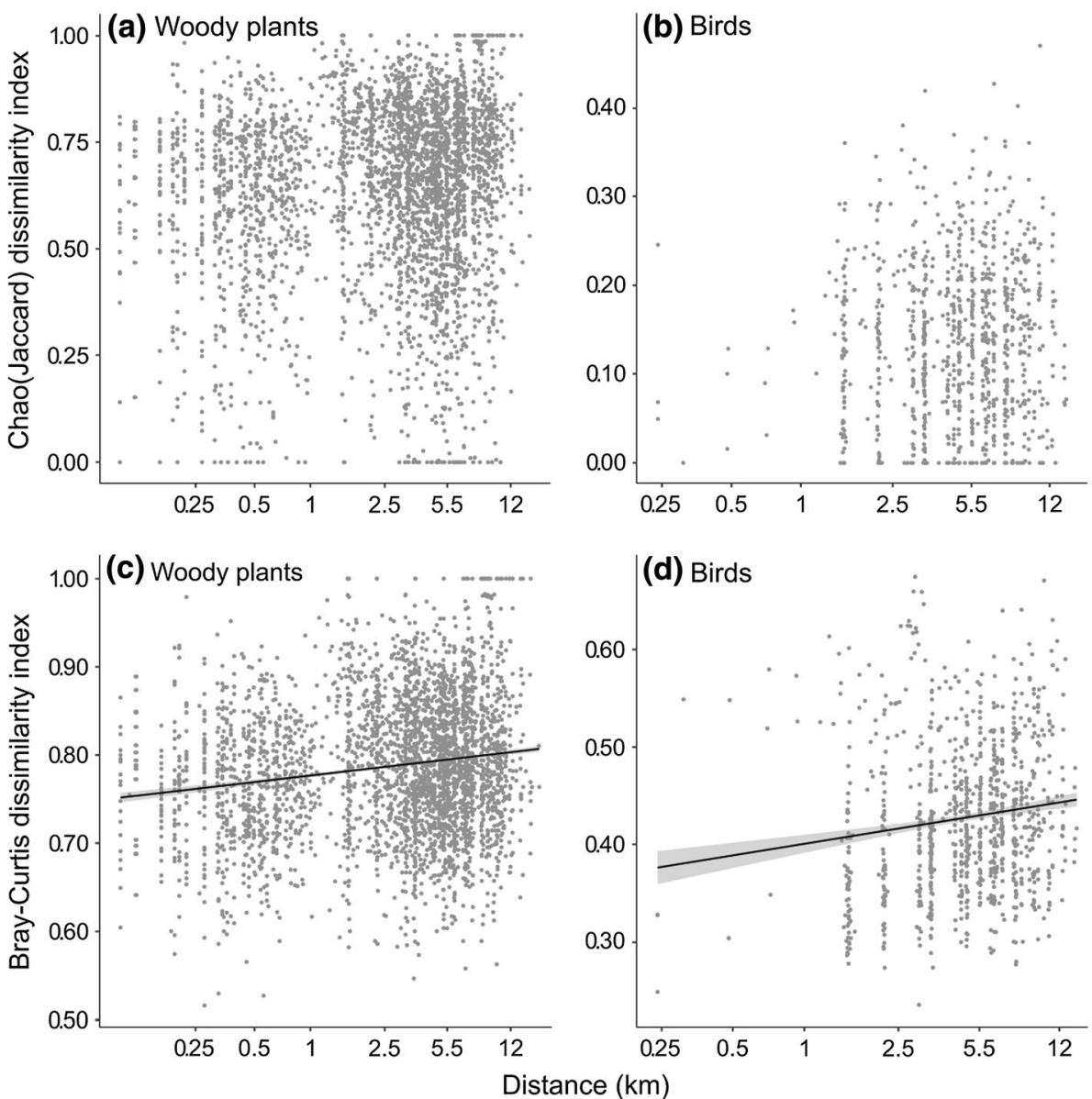
Fig. 5 Canonical Correspondence Analysis (CCA) ordination diagram showing composition of woody plants (centroids with plant species codes) and influence of elevation as a primary predictor after the effect of space was filtered out (total variation $=10.079$, axis 1 eigenvalue $=0.236$, axis 2 eigen value $=0.195$ ). The diagram displays 50 species with the highest fit value. Corresponding full species names are provided in Table S2

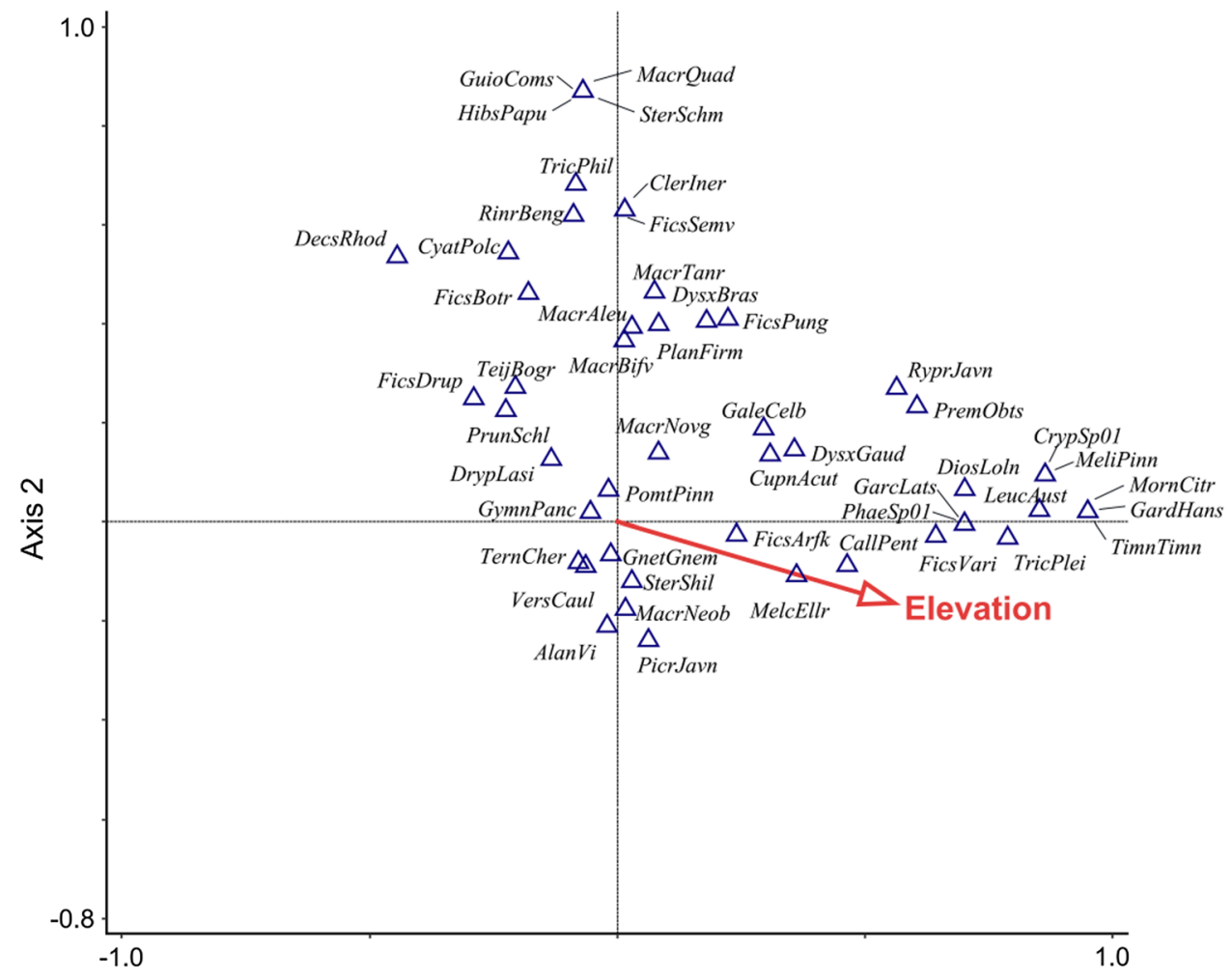

Axis 1

\section{Discussion}

The scale-dependent nature of diversity patterns has long been recognized in the field of ecology (Arrhenius 1921; Connor and McCoy 1979; Shmida and Wilson 1985; Huston 1999; Gaston 2000; Rahbek 2005). Studies exploring this relationship tend to draw a distinction between "local" diversity, determined mostly by species niche differentiation and direct inter-specific interactions, and "regional" diversity determined by species pools and evolutionary dynamics. However, few studies have focussed on the species diversity patterns on spatial scales between these two extremes, within tens to thousands of $\mathrm{km}^{2}$ within relatively uniform habitats. This study relates diversity patterns of woody plants and birds on this intermediate scale, represented here by 100 $\mathrm{km}^{2}$ of a lowland rainforest, to the local patterns within a 50 ha forest plot.

The magnitude of bird species diversity and the rate of species accumulation with increasing sample size within the Wanang FDP was almost perfectly mirrored by that within the 10,000 ha WCA. The overlap in species composition between the data sets from 50 and 10,000 ha was also very high, suggesting that for bird diversity the FDP is representative of the wider area. Conversely, plant species richness was shown to be significantly higher across the WCA than within the selected plots from the FDP, although the 50 ha diversity still represented $88 \%$ of the species richness within
10,000 ha. Thus any hierarchical structure between WCA and FDP appears non-existent for birds and weak for plants.

Bird species composition did not show any trends over the 10,000 ha area, i.e. there was no increase in Chao-Jaccard dissimilarity with increasing distance between the compared pairs of samples. However, there was a slow but significant change in the community composition taking account of species abundances with distance. This pattern, in combination with the relatively large proportion of variability in species composition explained by environmental variables, suggests that most of the variability in bird communities is fine-grained, within $1 \mathrm{~km}$ distances and in response to vegetation structure and terrain. The contrasting results of the two indices suggest that any variability over the scale explored in this study is primarily driven by relatively few common species. Dissimilarity in woody plant species composition and community composition showed similar patterns to those of birds. Woody plants displayed a small, but non-significant $(p=0.069)$, increase in species dissimilarity with distance, while community dissimilarity accounting for species abundances was significant and similar to that of birds. In addition, when comparing the two datasets separately plants showed higher mean dissimilarity across the wider WCA than in the FDP for both indices, indicating higher variation in plant community and species composition at the intermediate than at the local scale. Such a result is in line with the expectation that variance between samples 
Fig. 6 Redundancy Analysis (RDA) ordination diagram showing composition of bird community (species arrows) in relation to elevation and canopy closure after the effect of space was filtered out (total variation $=9792.023$, axis 1 eigenvalue $=0.121$, axis 2 eigenvalue $=0.042$ ). The 40 species with the highest fit value are displayed. Corresponding full species names are provided in Table S3

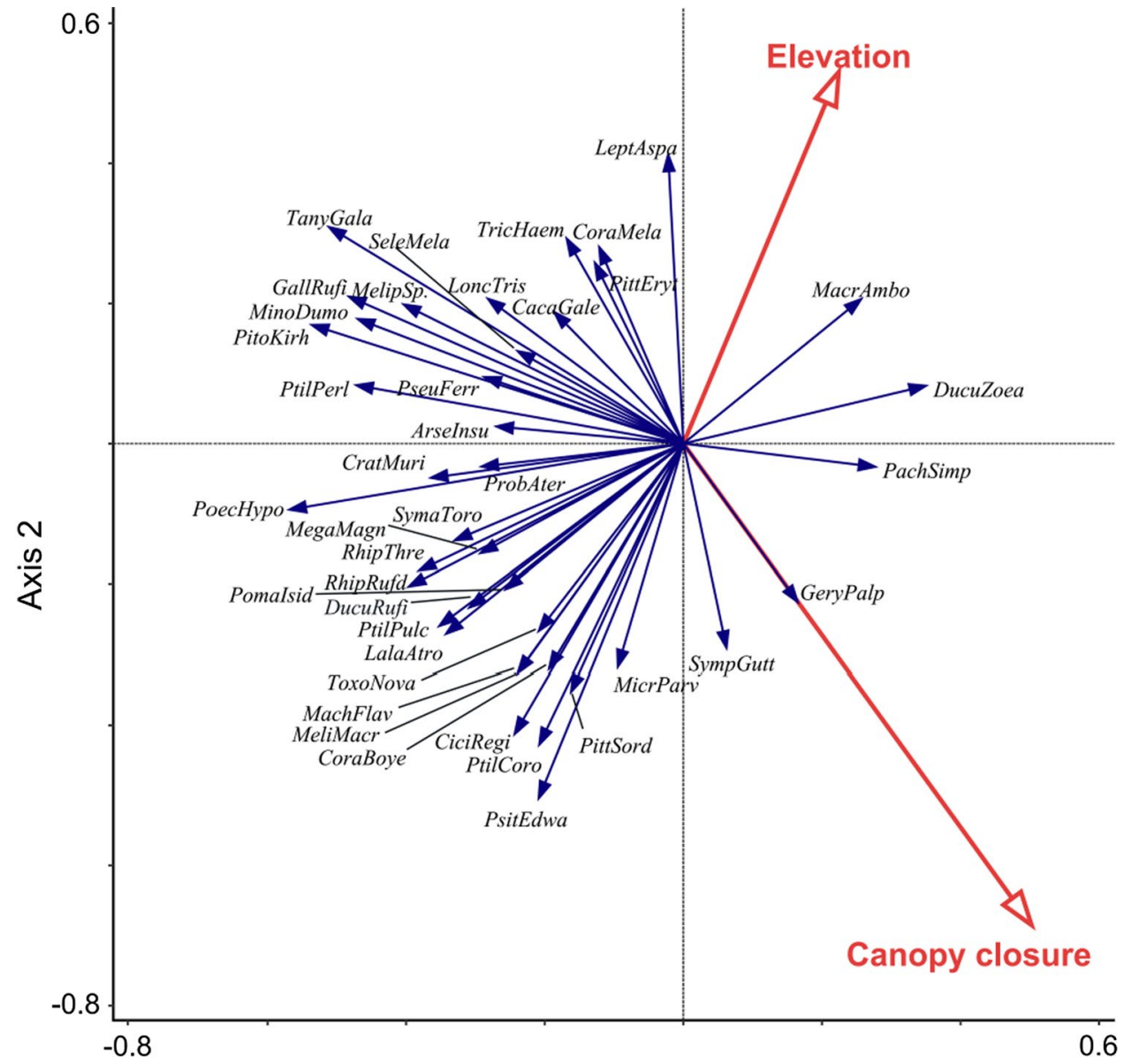

Axis 1 of a constant grain size should increase with increasing sample extent (Wiens 1989). Birds showed a similar pattern between datasets for both indices, although displaying lower overall dissimilarity than plants in all cases.

The difference in compositional dissimilarity patterns between plants and birds, while subtle, may be attributable to different ecological processes acting on the two taxa at the scales explored in this study. It is posited that dispersal limitation is a significant causal factor of species aggregation in tropical forest trees (Seidler and Plotkin 2006; Myers et al. 2013), with non-animal dispersed tree species likely to be dispersal-limited across spatial scales (Seidler and Plotkin 2006; Beaudrot et al. 2013). Evidence from tropical forest dynamics plots points to abiotic environmental filtering also being an important driver of tropical tree species distributions, at least at small $(<1 \mathrm{~km})$ scales (Plotkin et al. 2002). Our results suggest that distance between sampling locations may account for a relatively large proportion of variability in woody plant species composition when compared with environmental characteristics. However, because we only used elevation as an environmental predictor, these results should be interpreted with caution. As a highly mobile taxon, birds are less restricted in their dispersal than plants (Soininen et al. 2007), especially in unfragmented lowland habitats such as the one studied here (Van Houtan et al. 2007). Although the results of this study suggest bird species composition is related to habitat structure at fine scales, we found very little variation across the (relatively environmentally homogenous) broader scale of the WCA. Taken together, these observations suggest that dispersal limitation, perhaps driven primarily by limited dispersal of non-fleshy fruited (i.e. non-bird dispersed) trees, is a key factor in explaining the distribution differences observed between the two taxa. However, a current lack of studies on lowland rainforest beta-diversity at this scale limits scope for comparative assessment.

On comparing two separate 100 ha plots located within a 650 ha reserve in the Ecuadorian Amazon, Blake (2007) found bird species composition to be almost identical between plots, the only major variation being in individual species' distributions and abundances, reflecting small-scale differences in habitat structure and availability between plots. In a broader analysis of plots across French Guiana, Thiollay (2002) found that despite having sparse local 
populations, the vast majority of bird species had wide range sizes, thus masking any general determinant of community structure. Species turnover between sites was found to be $29 \%$ on average, for inter-site distances $15-320 \mathrm{~km}$, i.e. far higher than the distances analysed in this study.

In an analysis of plant beta-diversity from sites across Panama, Ecuador and Peru, Condit et al. (2002) showed that in the range of pairwise distances represented in this study (approximately $0-15 \mathrm{~km}$ ), percentage of shared plant species between plots decreased in all three regions. In both Ecuador and Peru, this decrease tended to level off beyond around $20 \mathrm{~km}$, suggesting that in these cases local- and intermediate-scale variation plays a more important role in determining plant community composition than broaderscale patterns. In a tropical dry forest in southern Mexico, Gallardo-Cruz et al. (2010) demonstrated a similar pattern of decreasing plant community similarity with increasing distance, in this case within a range of $0-6 \mathrm{~km}$. In a Malaysian lowland rainforest, the extent to which a 50 ha ForestGEO plot represented the wider peninsular flora was found to vary dramatically among plant families, with representativeness within large families ranging between 5 and 66\% (LaFrankie 1996).

The results of this study and those described above highlight the varying importance of so-called intermediate-scale patterns in determining overall community composition for different taxa, and therefore in determining optimal sampling regimes. The relative homogeneity of bird communities across the WCA suggests that bird species richness and community composition across 10,000 ha of lowland rainforest may be accurately estimated by sampling within a 50 ha plot. This result is particularly notable given the lack of previous studies on birds in ForestGEO plots. For plants however, surveys that are limited to 50 ha may miss a significant proportion of diversity due to the higher influence of local-scale variation on overall community composition in woody plants. Nevertheless, the observed slow distance decay of both woody plants and birds across the WCA provides support for the use of the ForestGEO Plot as a means of representing wider biodiversity for both taxa. Extending the study of intermediate-scale diversity patterns to important rainforest taxa such as insects will be necessary if we are to gain a fuller picture of biodiversity across spatial scales in lowland rainforests.

Supplementary Information The online version contains supplementary material available at https://doi.org/10.1007/s00442-021-04925-8.

Acknowledgements We would like to thank Filip Damen and the Wanang community for allowing us to carry out data collection on their land and for assisting in research activities. We personally thank Mark Mulau, Saki Francis, Fred Las, Jessy Paul, Jory Umbang, Samuel Jepi and Mulapa Kepe for their assistance in data collection. We are grateful to Katerina Sam and Legi Sam for providing advice on fieldwork protocols. For logistical support and assistance in procuring provisions for fieldwork we thank the staff members at New Guinea Binatang Research Centre, and especially Clant Alok for his work in ensuring temporary camps were set up for data collection across the Wanang Conservation Area.

Author contributions statement $\mathrm{RJH}, \mathrm{KC}$ and $\mathrm{VN}$ conceived the study; $\mathrm{RJH}, \mathrm{KC}, \mathrm{LP}, \mathrm{GSK}$ and $\mathrm{KM}$ conducted the fieldwork (assisted by others mentioned in acknowledgements); $\mathrm{KC}$ and $\mathrm{RJH}$ analysed the data with assistance from JR and PF; RJH led the writing with inputs from $\mathrm{KC}$, VN, MRP, AJAS, PF, JR and GW.

Funding We acknowledge the funding support of the Holly Hill Trust and the Grant Agency of the Czech Republic (grants 19-28126X and 20-17282S), as well as the Swire and Sons Co. and the UK Darwin Initiative for Survival of Species (19-008) for supporting the Wanang Conservation Area.

Data availability The datasets generated during the current study will be made publicly available in the Dryad repository, upon publication of the manuscript.

\section{Declarations}

Conflict of interest The authors have no relevant financial or nonfinancial interests to disclose. The organisations providing research grants for this study do not stand to gain or lose financially through publication of this manuscript.

Ethics Data collection did not involve invasive sampling techniques and animals were not removed from their habitats or manipulated in any way, therefore based on ethics assessment, no approval was required.

Statement of Legality All fieldwork activities complied with the current laws of Papua New Guinea.

Open Access This article is licensed under a Creative Commons Attribution 4.0 International License, which permits use, sharing, adaptation, distribution and reproduction in any medium or format, as long as you give appropriate credit to the original author(s) and the source, provide a link to the Creative Commons licence, and indicate if changes were made. The images or other third party material in this article are included in the article's Creative Commons licence, unless indicated otherwise in a credit line to the material. If material is not included in the article's Creative Commons licence and your intended use is not permitted by statutory regulation or exceeds the permitted use, you will need to obtain permission directly from the copyright holder. To view a copy of this licence, visit http://creativecommons.org/licenses/by/4.0/.

\section{References}

Anderson-Teixeira KJ, Davies SJ, Bennett AC, Gonzalez-Akre EB, Muller-Landau HC, Wright SJ, Abu Salim K, Almeyda Zambrano AM, Alonso A, Baltzer JL, Basset Y, Bourg NA, Broadbent EN, Brockelman WY, Bunyavejchewin S, Burslem DFRP, Butt N, Cao M, Cardenas D, Chuyong GB, Clay K, Cordell S, Dattaraja HS, Deng X, Detto M, Du X, Duque A, Erikson DL, Ewango CEN, Fischer GA, Fletcher C, Foster RB, Giardina CP, Gilbert GS, Gunatilleke N, Gunatilleke S, Hao Z, Hargrove WW, Hart TB, Hau BCH, He F, Hoffman FM, Howe RW, Hubbell SP, 
Inman-Narahari FM, Jansen PA, Jiang M, Johnson DJ, Kanzaki M, Kassim AR, Kenfack D, Kibet S, Kinnaird MF, Korte L, Kral K, Kumar J, Larson AJ, Li Y, Li X, Liu S, Lum SKY, Lutz JA, Ma K, Maddalena DM, Makana JR, Malhi Y, Marthews T, Mat Serudin R, Mcmahon SM, McShea WJ, Memiaghe HR, Mi X, Mizuno T, Morecroft M, Myers JA, Novotny V, de Oliveira AA, Ong PS, Orwig DA, Ostertag R, den Ouden J, Parker GG, Phillips RP, Sack L, Sainge MN, Sang W, Sri-ngernyuang K, Sukumar R, Sun IF, Sungpalee W, Suresh HS, Tan S, Thomas SC, Thomas DW, Thompson J, Turner BL, Uriarte M, Valencia R, Vallejo MI, Vicentini A, Vrška T, Wang X, Wang X, Weiblen G, Wolf A, Xu H, Yap S, Zimmerman J (2015) CTFS-ForestGEO: A worldwide network monitoring forests in an era of global change. Glob Chang Biol 21:528-549. https://doi.org/10.1111/gcb.12712

Arrhenius O (1921) Species and area. J Ecol 9:95-99. https://doi. org/10.2307/2255763

Ashton PS (1995) What can be learned from a 50-ha plot which cannot be learned any other way? In: Lee H, Ashton P, Ogino $\mathrm{K}$ (eds) Long term ecological research of tropical rain forest in Sarawak. studies of global environmental change with special reference to Asia and pacific Regions. Ehime University, Matsuyama, pp 207-220

Barton PS, Cunningham SA, Manning AD, Gibb H, Lindenmayer DB, Didham RK (2013) The spatial scaling of beta diversity. Glob Ecol Biogeogr 22:639-647. https://doi.org/10.1111/geb. 12031

Basset Y, Cizek L, Cuenoud P, Didham RK, Guilhaumon F, Missa O, Novotny V, Odegaard F, Roslin T, Schmidl J, Tishechkin AK, Winchester NN, Roubik DW, Aberlenc H-P, Bail J, Barrios H, Bridle JR, Castano-Meneses G, Corbara B, Curletti G, Duarte da Rocha W, De Bakker D, Delabie JHC, Dejean A, Fagan LL, Floren A, Kitching RL, Medianero E, Miller SE, Gama de Oliveira E, Orivel J, Pollet M, Rapp M, Ribeiro SP, Roisin Y, Schmidt JB, Sorensen L, Leponce M (2012) Arthropod diversity in a tropical forest. Science 338:1481-1484. https://doi.org/10. 1126/science. 1226727

Beaudrot L, Rejmánek M, Marshall AJ (2013) Dispersal modes affect tropical forest assembly across trophic levels. Ecography 36:984-993. https://doi.org/10.1111/j.1600-0587.2013.00122.x

Bibby CJ, Burgess ND, Hill DA (2000) bird census techniques, 2nd edn. Academic Press, London

Blake JG (2007) Neotropical forest bird communities: a comparison of species richness and composition at local and regional scales. Condor 109:237-255. https://doi.org/10.1650/0010-5422(2007) 109

Chao A, Chazdon RL, Colwell RK, Shen T-J (2005) A new statistical approach for assessing similarity of species composition with incidence and abundance data. Ecol Lett 8:148-159. https://doi. org/10.1111/j.1461-0248.2004.00707.x

Chao A, Gotelli NJ, Hsieh TC, Sander EL, Colwell RK (2014) Rarefaction and extrapolation with Hill numbers: a framework for sampling and estimation in species diversity studies. Ecol Monogr 84:45-67. https://doi.org/10.1890/13-0133.1

Chase JM (2014) Spatial scale resolves the niche versus neutral theory debate. J Veg Sci 25:319-322. https://doi.org/10.1111/ jvs. 12159

Chen Y, Wright SJ, Muller-Landau HC, Hubbell SP, Wang Y, Yu S (2016) Positive effects of neighborhood complementarity on tree growth in a Neotropical forest. Ecology 97:776-785. https://doi. org/10.1890/15-0625.1

Colwell RK, Coddington JA (1994) Estimating terrestrial biodiversity through extrapolation. Philos Trans Biol Sci 345:101-118. https:// doi.org/10.2307/3544596

Condit R (1995) Research in large, long-term tropical forest plots. Trends Ecol Evol 10:18-22. https://doi.org/10.1016/S01695347(00)88955-7
Condit R (1998) Tropical forest census plots: methods and results from Barro Colorado Island, Panama and a comparison with other plots. Springer-Verlag, Berlin

Condit R, Hubbell SP, Lafrankie JV, Sukumar R, Manokaran N, Foster RB, Ashton PS (1996) Species-area and species-individual relationships for tropical trees: a comparison of three 50-ha plots. J Ecol 84:549-562. https://doi.org/10.2307/2261477

Condit R, Pitman NCA, Leigh EG Jr, Chave J, Terborgh J, Foster RB, Núñez VP, Aguilar S, Valencia R, Villa G, Muller-Landau HC, Losos E, Hubbell SP (2002) Beta-diversity in tropical forest trees. Science 295:666-669. https://doi.org/10.1126/science.1066854

Connor EF, McCoy ED (1979) The statistics and biology of the species-area relationship. Am Nat 113:791-833. https://doi.org/10. $1086 / 283438$

Crawley MJ, Harral JE (2001) Scale dependence in plant biodiversity. Science 291:864-868. https://doi.org/10.1126/science.291. 5505.864

De Cáceres M, Legendre P, Valencia R, Cao M, Chang LW, Chuyong G, Condit R, Hao Z, Hsieh CF, Hubbell S, Kenfack D, Ma K, Mi X, Supardi Noor MN, Kassim AR, Ren H, Su SH, Sun IF, Thomas D, Ye W, He F (2012) The variation of tree beta diversity across a global network of forest plots. Glob Ecol Biogeogr 21:1191-1202. https://doi.org/10.1111/j.1466-8238.2012. 00770.x

Field R, Hawkins BA, Cornell HV, Currie DJ, Diniz-Filho JAF, Guégan JF, Kaufman DM, Kerr JT, Mittelbach GG, Oberdorff T, O’Brien EM, Turner JRG (2009) Spatial species-richness gradients across scales: a meta-analysis. J Biogeogr 36:132-147. https://doi.org/ 10.1111/j.1365-2699.2008.01963.x

Freestone AL, Inouye BD (2006) Dispersal limitation and environmental heterogeneity shape scale-dependent diversity patterns in plant communities. Ecology 87:2425-2432. https://doi.org/10. 1890/0012-9658(2006)87[2425:DLAEHS]2.0.CO;2

Gallardo-Cruz J, Meave J, Pérez-García E, Hernández-Stefanoni J (2010) Spatial structure of plant communities in a complex tropical landscape: implications for $\beta$-diversity. Community Ecol 11:202-210. https://doi.org/10.1556/comec.11.2010.2.8

Gaston KJ (2000) Global patterns in biodiversity. Nature 405:220-227. https://doi.org/10.1038/35012228

Gotelli NJ, Colwell RK (2001) Quantifying biodiversity: procedures and pitfalls in the measurement and comparison of species richness. Ecol Lett 4:379-391. https://doi.org/10.1046/j.1461-0248. 2001.00230.x

Hsieh TC, Ma KH, Chao A (2016) iNEXT: An R package for rarefaction and extrapolation of species diversity (Hill numbers). Methods Ecol Evol 7:1451-1456. https://doi.org/10.1111/2041210X.12613

Hubbell SP (2001) The unified neutral theory of biodiversity and biogeography. Princeton University Press, Princeton

Hubbell SP, Foster RB (1983) Diversity of canopy trees in a neotropical forest and implications for conservation. In: Sutton S, Whitmore T, Chadwick A (eds) Tropical rain forest: ecology and management. Blackwell Scientific Publications, Oxford, pp 25-41

Huston MA (1999) Local processes and regional patterns: appropriate scales for understanding variation in the diversity of plants and animals. Oikos 86:393-401. https://doi.org/10.2307/3546645

Idárraga Á, Duque-Montoya ÁJ, Feeley K (2016) Divergent drivers of tree community composition in lowland and highland forests of the northern tropical Andes, Colombia. Actual Biol 38:145-156. https://doi.org/10.17533/udea.acbi.v37n105a02

Jackson HB, Fahrig L (2015) Are ecologists conducting research at the optimal scale? Glob Ecol Biogeogr 24:52-63. https://doi.org/ $10.1111 /$ geb. 12233

Jankowski JE, Merkord CL, Rios WF, Cabrera KG, Revilla NS, Silman MR (2013) The relationship of tropical bird communities to tree species composition and vegetation structure along an Andean 
elevational gradient. J Biogeogr 40:950-962. https://doi.org/10. 1111/jbi.12041

Kenfack D, Thomas DW, Chuyong G, Condit R (2007) Rarity and abundance in a diverse African forest. Biodivers Conserv 16:2045-2074. https://doi.org/10.1007/s10531-006-9065-2

Kochummen KM, LaFrankie JV (1990) Floristic composition of Pasoh forest reserve, a lowland rain forest in peninsular Malaysia. J Trop For Sci 3:1-13

Korhonen L, Heikkinen J (2009) Automated analysis of in situ canopy images for the estimation of forest canopy cover. For Sci 55:323334. https://doi.org/10.1093/forestscience/55.4.323

Lafrankie J (1996) Distribution and abundance of Malayan trees: Significance of family characteristics for conservation. Gard Bull Singap 48:75-87

Laliberté E, Paquette A, Legendre P, Bouchard A (2008) Assessing the scale-specific importance of niches and other spatial processes on beta diversity: a case study from a temperate forest. Oecologia 159:377-388. https://doi.org/10.1007/s00442-008-1214-8

Lee HS, Davies SJ, Lafrankie JV, Tan S, Yamakura T, Itoh A, Ohkubo T, Ashton PS (2002) Floristic and structural diversity of mixed dipterocarp forest in Lambir Hills National Park, Sarawak, Malaysia. J Trop For Sci 14:379-400

Legendre P, Legendre L (2012) Numerical ecology. Elsevier Science $\mathrm{BV}$, Amsterdam

Lennon JJ, Kolefft P, Greenwood JJD, Gaston KJ (2001) The geographical structure of British bird distributions: diversity, spatial turnover and scale. J Anim Ecol 70:966-979. https://doi.org/10. 1046/j.0021-8790.2001.00563.x

Macarthur R, Levins R (1967) The limiting similarity, convergence, and divergence of coexisting species. Am Nat 101:377-385

MacArthur JW, Wilson EO (1967) The theory of island biogeography. Princeton University Press, Princeton

MacGregor-Fors I, Payton ME (2013) Contrasting diversity values: statistical inferences based on overlapping confidence intervals. PLoS ONE 8:8-11. https://doi.org/10.1371/journal.pone.0056794

Mathworks (2015) Image Processing Toolbox (version 2015a). Natick, Framingham

Melchior LG, de Rossa-Feres DC, da Silva FR (2017) Evaluating multiple spatial scales to understand the distribution of anuran beta diversity in the Brazilian Atlantic Forest. Ecol Evol 7:2403-2413. https://doi.org/10.1002/ece3.2852

Metz MR (2012) Does habitat specialization by seedlings contribute to the high diversity of a lowland rain forest? J Ecol 100:969-979. https://doi.org/10.1111/j.1365-2745.2012.01972.x

Myers JA, Chase JM, Jiménez I, Jørgensen PM, Araujo-Murakami A, Paniagua-Zambrana N, Seidel R (2013) Beta-diversity in temperate and tropical forests reflects dissimilar mechanisms of community assembly. Ecol Lett 16:151-157. https://doi.org/10.1111/ ele. 12021

Nekola JC, White PS (1999) The distance decay of similarity in biogeography and ecology. J Biogeogr 26:867-878. https://doi.org/ 10.1046/j.1365-2699.1999.00305.x

Novotny V, Drozd P, Miller SE, Kulfan M, Janda M, Basset Y, Weiblen GD (2006) Why are there so many species of herbivorous insects in tropical rainforests? Science 313:1115-1118. https://doi.org/ $10.1126 /$ science. 1129237

Oksanen J, Blanchet FG, Friendly M, Kindt R, Legendre P, Mcglinn D, Minchin PR, O'Hara RB, Simpson GL, Solymos P, Stevens MHH, Szoecs E (2018) vegan: Community Ecology Package. R package version $2.5-3$

Paijmans K (1976) New guinea vegetation. Australia National University Press, Canberra

Plotkin JB, Potts MD, Yu DW, Bunyavejchewin S, Condit R, Foster R, Hubbell S, LaFrankie J, Manokaran N, Lee HS, Sukumar R, Nowak MA, Ashton PJ (2001) Predicting species diversity in tropical forests. Proc Natl Acad Sci USA 97:10850-10854
Plotkin JB, Chave J, Ashton PS (2002) Cluster analysis of spatial patterns in Malaysian tree species. Am Nat 160:629-644. https://doi. org/10.2307/3079114

Qian H (2009) Global comparisons of beta diversity among mammals, birds, reptiles, and amphibians across spatial scales and taxonomic ranks. J Syst Evol 47:509-514. https://doi.org/10.1111/j.17596831.2009.00043.x

Rahbek C (2005) The role of spatial scale and the perception of largescale species-richness patterns. Ecol Lett 8:224-239. https://doi. org/10.1111/j.1461-0248.2004.00701.x

Rahbek C, Graves GR (2001) Multiscale assessment of patterns of avian species richness. Proc Natl Acad Sci 98:4534-4539. https:// doi.org/10.1073/pnas.071034898

Reif J, Storch D, Śímová I (2008) The effect of scale-dependent habitat gradients on the structure of bird assemblages in the Czech Republic. Acta Ornithol 43:197-206. https://doi.org/10.3161/ $000164508 X 395315$

Rosindell J, Hubbell SP, Etienne RS (2011) The unified neutral theory of biodiversity and biogeography at age ten. Trends Ecol Evol 26:340-348. https://doi.org/10.1016/j.tree.2011.03.024

Scheiner SM, Cox SB, Willig M, Mittelbach GG, Osenberg C, Kaspari M (2000) Species richness, species-area curves and Simpson's paradox. Evol Ecol Res 2:791-802

Schulze CH, Waltert M, Kessler PJA, Pitopang R, Shahabuddin VD, Mühlenberg M, Gradstein SR, Leuschner C, Steffan-Dewenter I, Tscharntke T (2004) Biodiversity indicator groups of tropical land-use systems: comparing plants, birds, and insects. Ecol Appl 14:1321-1333. https://doi.org/10.1890/02-5409

Seidler TG, Plotkin JB (2006) Seed dispersal and spatial pattern in tropical trees. PLoS Biol 4:2132-2137. https://doi.org/10.1371/ journal.pbio.0040344

Shmida A, Wilson MV (1985) Biological determinants of species diversity. J Biogeogr 12:1. https://doi.org/10.2307/2845026

Smilauer P, Leps J (2014) Multivariate analysis of ecological data using Canoco 5. Cambridge University Press, Cambridge

Soininen J, Lennon JJ, Hillebrand H (2007) A multivariate analysis of beta diversity across organisms and environment. Ecology 88:2830-2838. https://doi.org/10.1890/06-1730.1

Thiollay J-M (2002) Avian diversity and distribution in French Guiana: patterns across a large forest landscape. J Trop Ecol 18:471-498. https://doi.org/10.1017/S026646740200233X

Van Houtan KS, Pimm SL, Halley JM, Bierregaard RO, Lovejoy TE (2007) Dispersal of Amazonian birds in continuous and fragmented forest. Ecol Lett 10:219-229. https://doi.org/10.1111/j. 1461-0248.2007.01004.x

Vandermeer JH (1972) Niche theory. Annu Rev Ecol Syst 3:107-132. https://doi.org/10.1146/annurev.es.03.110172.000543

Veech JA, Crist TO (2007) Habitat and climate heterogeneity maintain beta-diversity of birds among landscapes within ecoregions. Glob Ecol Biogeogr 16:650-656. https://doi.org/10.1111/j.1466-8238. 2007.00315.x

Vincent JB, Henning B, Saulei S, Sosanika G, Weiblen GD (2015) Forest carbon in lowland Papua New Guinea: Local variation and the importance of small trees. Austral Ecol 40:151-159. https:// doi.org/10.1111/aec.12187

Volkov I, Banavar JR, He F, Hubbell SP, Maritan A (2005) Density dependence explains tree species abundance and diversity in tropical forests. Nature 438:658-661. https://doi.org/10.1038/ nature 04030

Volkov I, Banavar JR, Hubbell SP, Maritan A (2009) Inferring species interactions in tropical forests. PNAS 106:13854-13859. https:// doi.org/10.1073/pnas.0903244106

Wiens JA (1989) Spatial scaling in ecology. Funct Ecol 3:385-397

Willis KJ, Whittaker RJ (2002) Species diversity-scale matters. Science 295:1245-1247. https://doi.org/10.1126/science.1067335 
Yang J, Swenson NG, Zhang G, Ci X, Cao M, Sha L, Li J, Ferry Slik JW, Lin L (2015) Local-scale partitioning of functional and phylogenetic beta diversity in a tropical tree assemblage. Sci Rep 5:1-10. https://doi.org/10.1038/srep12731
Zellweger F, Roth T, Bugmann H, Bollmann K (2017) Beta diversity of plants, birds and butterflies is closely associated with climate and habitat structure. Glob Ecol Biogeogr 26:898-906. https:// doi.org/10.1111/geb.12598 